\title{
Microarray expression profile analysis of long non-coding RNAs in pancreatic ductal adenocarcinoma
}

\author{
YU ZHOU $^{1,3}$, BO GONG $^{1,3}$, ZHI-LIN JIANG ${ }^{1}$, SHAN ZHONG ${ }^{2}$, XING-CHAO LIU ${ }^{2}$, \\ $\mathrm{KE} \mathrm{DONG}^{2}$, HE-SHUI WU ${ }^{4}$, HONG-JI YANG ${ }^{2,3}$ and SHI-KAI ZHU ${ }^{2,3}$ \\ ${ }^{1}$ Sichuan Provincial Key Laboratory for Human Disease Gene Study and Institute of Laboratory Medicine, \\ ${ }^{2}$ Organ Transplant Center, Hospital of University of Electronic Science and Technology of China and \\ Sichuan Provincial People's Hospital; ${ }^{3}$ Medicine Information Center, School of Medicine, \\ University of Electronic Science and Technology of China, Chengdu, Sichuan 610072; \\ ${ }^{4}$ Department of Pancreatic Surgery, Union Hospital, Tongji Medical College, \\ Huazhong University of Science and Technology, Wuhan, Hubei 430022, P.R. China
}

Received October 7, 2015; Accepted November 8, 2015

DOI: 10.3892/ijo.2015.3292

\begin{abstract}
Long non-coding RNA (lncRNA) is a variety of the human transcriptome that does not code for proteins and plays an important role in the development and progression of multiple solid malignant tumors. However, the roles of IncRNAs in the development of pancreatic ductal adenocarcinoma (PDAC) remain unknown. In this study, we investigated the expression patterns of lncRNAs in three PDAC tumor samples (T) relative to those of matched adjacent non-tumor tissues $(\mathrm{N})$ via a microarray with 30,586 lncRNA probes and 26,109 mRNA probes. The lncRNA microarray revealed 27,279 lncRNAs in PDAC samples, of which 2,331 were significantly upregulated $(\mathrm{P}<0.05 ; \mathrm{T} / \mathrm{N}>2.0)$ and 1,641 were downregulated $(\mathrm{P}<0.05 ; \mathrm{N} / \mathrm{T}>2.0)$ compared with matched adjacent non-tumor samples. In addition, 19,995 mRNAs were detected, of which 1,676 were significantly upregulated $(\mathrm{P}<0.05 ; \mathrm{T} / \mathrm{N}>2.0)$ and 1,981 were downregulated $(\mathrm{P}<0.05 ;$ $\mathrm{N} / \mathrm{T}>2.0$ ). Pathway analysis indicated that 41 pathways corresponded to upregulated transcripts and 25 pathways corresponded to downregulated transcripts (P-value cut-off is 0.05$)$. Gene ontology (GO) analysis showed that the highest enriched GOs targeted by upregulated and downregulated transcripts were tissue homeostasis. The validation results from quantitative reverse transcription polymerase chain reaction (qRT-PCR) analysis and microarray analysis were
\end{abstract}

Correspondence to: Professor Shi-Kai Zhu or Professor Hong-Ji Yang, Organ Transplant Center, Hospital of University of Electronic Science and Technology of China and Sichuan Provincial People's Hospital, Chengdu, Sichuan 610072, P.R. China

E-mail: zhushikai37@163.com

E-mail: hongjiyang@hotmail.com

Key words: long non-coding RNA, pancreatic ductal adenocarcinoma, microarray, HOTAIRM1 consistent. Furthermore, the expression level of long intergenic non-coding RNA HOTAIRM1 was upregulated in 12 PDAC tissues samples compared with matched adjacent non-tumor samples by qRT-PCR. The results showed that the lncRNA and mRNA expression profiles differed significantly between the PDAC tissues and their adjacent non-tumor tissues, and the revelation of an association between HOTAIRM1 expression and PDAC is especially noteworthy. These findings may provide new potential molecular markers for diagnosis and treatment of PDAC.

\section{Introduction}

Pancreatic ductal adenocarcinoma (PDAC), a common digestive system cancer, is highly malignant and has a poor disease outcome. Despite the progress in the understanding of the molecular and genetic basis of this disease, the 5-year survival rate has remained low and usually does not exceed 5\%. Only $20-25 \%$ of the patients present with potentially resectable disease, and surgery represents the only chance for a cure $(1,2)$. PDAC is considered as a systemic disease because of the high rate of relapse after curative surgery in patients with resectable disease at diagnosis. Enormous efforts have been made to identify the special molecular markers for PDAC, which show vast application prospect as targets for the disease treatment. The research fields of molecular markers for PDAC include proteins, such as K-Ras, p16, and SMAD4 (3-5); miRNAs, such as miR-210 and miR-221 (6-8); and the recently research hotspot the IncRNAs.

Long non-coding RNAs (lncRNAs) refer to a group of RNAs that are usually more than 200 nucleotides and are not involved in protein generation (9). Recent studies have begun to associate subsets of lncRNAs to specific regulatory mechanisms of important biological processes, including cell proliferation, survival, differentiation, and chromatin remodeling both in cis and in trans (10-19). Many functional lncRNAs have been shown to play key roles in organ development and cancer. Some lncRNAs act as tumor suppressor; 
others participate in cellular replicative immortality, or even regulate angiogenesis and metastasis $(20,21)$. Previous studies have reported several lncRNA, such as HOTAIR, MALAT1 and PVT1 (22-24), which revealed the significance of lncRNAs in the regulation of multiple biological processes at different levels that may served as molecular markers for several cancer. However, the roles of IncRNAs in the progression of PDAC remain not well identified.

To evaluate the expression profile and identify the special lncRNAs in PDAC, we interrogated the differentially expression profiles of lncRNAs and mRNAs between 3 PDAC samples and their matched adjacent non-tumor samples via microarray. Gene ontology (GO) analysis, pathway analysis and network analysis was done for further investigation. Quantitative reverse transcription polymerase chain reaction (qRT-PCR) was used to validate several random upregulated and downregulated lncRNAs in the 3 PDAC tissues. Further, HOTAIRM1, one of thousands of deregulated lncRNAs we identified, was further evaluated in 12 pairs of matched tumor /non-tumor (T/N) tissues via qRT-PCR. This study uncovers the aberrant expression of lncRNAs in PDAC tissues, and may contribute to understanding of the mechanism of PDAC progression and provide new potential molecular markers for diagnosis and treatment of PDAC.

\section{Materials and methods}

Patients and tissue samples. A total of twelve PDAC tissue samples and their matched adjacent non-tumor samples were obtained with informed consent from PDAC patients at Department of Surgery, Sichuan Provincial People's Hospital. The diagnosis of all patients was confirmed based on the WHO classification and staged according to the tumor node metastasis classification and were reviewed by two pathologists. Clinical parameters were recorded for each sample, included age, gender, location of tumor, vascular permeation, TNM stage and differentiation. Samples were taken during surgery, immediately frozen in liquid nitrogen, and stored at $-80^{\circ} \mathrm{C}$ for further analysis. Paired tumor and non-tumor tissues from three PDAC patients were used for the microarray assay. Twelve paired PDAC tissues (not including the 3 paired tissues used for microarray) were used for the qRT-PCR validation assay. The analysis of human tissues were approved by the Human Research Ethics Committee of Sichuan Provincial People's Hospital, and all PDAC patients gave written informed consent for the use of clinical samples for medical research.

RNA isolation. Total RNA was isolated from the 15 PDAC tissues and paired non-tumor tissues using TRIzol reagent (Invitrogen, CA, USA), and quantified using a NanoDrop ND-1000 spectrophotometer (NanoDrop, DE, USA). The integrity of RNA was assessed by standard denaturing agarose gel electrophoresis, and the purity was estimated by the ratio of absorbance at 260-280 $\mathrm{nm}$.

Microarray. Arraystar Human LncRNA Microarray V3.0 is designed for the global profiling of human lncRNAs and protein-coding transcripts, which is updated from the previous Microarray V2.0. Approximately 30,586 lncRNAs and 26,109 coding transcripts can be detected by our third-generation lncRNA microarray. The lncRNAs are carefully constructed using the most highly respected public transcriptome databases (including Refseq, UCSC known genes, and Gencode), as well as landmark publications. Each transcript is represented by a specific exon or splice junction probe, which can identify individual transcript accurately. Positive probes for housekeeping genes and negative probes are also printed onto the array for hybridization quality control.

RNA labeling and array hybridization. Sample labeling and array hybridization were performed according to the Agilent One-Color Microarray-Based Gene Expression Analysis protocol (Agilent Technology) with minor modifications. Briefly, mRNA was purified from total RNA after removal of rRNA (mRNA-ONLY ${ }^{\mathrm{TM}}$ Eukaryotic mRNA Isolation kit, Epicentre). Then, each sample was amplified and transcribed into fluorescent cRNA along the entire length of the transcripts without 3' bias utilizing a random priming method (Arraystar Flash RNA Labeling kit, Arraystar). Each labeled cRNA $(1 \mu \mathrm{g})$ was fragmented by adding $5 \mu \mathrm{l} 10 \mathrm{X}$ blocking agent and $1 \mu \mathrm{l}$ of $25 \mathrm{X}$ fragmentation buffer, then heated the mixture at $60^{\circ} \mathrm{C}$ for $30 \mathrm{~min}$, finally $25 \mu \mathrm{l} 2 \mathrm{X}$ GE hybridization buffer was added to dilute the labeled cRNA. Hybridization solution $(50 \mu 1)$ was dispensed into the gasket slide and assembled to the IncRNA expression microarray slide. The slides were incubated for $17 \mathrm{~h}$ at $65^{\circ} \mathrm{C}$ in an Agilent Hybridization Oven. The hybridized arrays were washed, fixed and scanned with using the Agilent DNA Microarray Scanner (part number G2505C).

Data analysis. Data analysis were performed by KangChen Biotech (Shanghai, China). Agilent Feature Extraction software (version 11.0.1.1) was used to analyze acquired array images. Quantile normalization and subsequent data processing were performed with using the Gene Spring GX v12.1 software package (Agilent Technologies). After quantile normalization of the raw data, IncRNAs and mRNAs of $\geq 3$ out of 6 samples have flags in Present or Marginal (All Targets Value) were chosen for further data analysis. Differentially expressed lncRNAs and mRNAs with statistical significance between the two groups were identified through P-value/ FDR filtering. Differentially expressed lncRNAs and mRNAs between the two samples were identified through fold-change filtering. Hierarchical clustering and combined analysis were performed using in-house scripts.

Quantitative real-time PCR ( $q R T-P C R)$. Total RNA was isolated using TRIzol reagent (Invitrogen) and then reverse transcribed using PrimeScript ${ }^{\circledR}$ RT Reagent kit with gDNA Eraser (Perfect Real Time) (Takara, Dalian, China) according to the manufacturer's instructions. The expression levels of seven upregulated and seven downregulated lncRNAs in the 3 patients included in the microarray study were measured by qRT-PCR using SYBR Green assays (Takara). The expression levels of HOTAIRM1 in twelve PDAC specimens and their paired adjacent non-cancerous tissues were also measured by qRT-PCR. The lncRNA expression differences between the matched cancer and non-cancerous samples were analyzed using Student's paired t-test with the IBM SPSS Statistics 
Table I. Clinical parameter of 15 PDAC patients.

\begin{tabular}{lcllcll}
\hline Sample nos. & Age (years) & Gender & Location of tumor & Vascular permeation & TNM stage & Differentiation \\
\hline 1 & 46 & Male & Head & Present & T2N1M0 & Poorly \\
2 & 53 & Female & Body and tail & Absent & T3N1M0 & Moderately \\
3 & 67 & Female & Head & Absent & T2N0M0 & Poorly \\
4 & 72 & Male & Head & Absent & T3N1M0 & Moderately \\
5 & 61 & Male & Body and tail & Present & T1N0M0 & Moderately \\
6 & 42 & Female & Body and tail & Absent & T2N1M0 & Poorly \\
7 & 55 & Male & Head & Absent & T1N0M0 & Well \\
8 & 56 & Male & Head & Absent & T2N0M0 & Well \\
9 & 75 & Male & Head & Absent & T4N1M0 & Moderately \\
10 & 52 & Female & Head & Absent & T2N0M0 & Poorly \\
11 & 60 & Male & Head & Absent & T1N1M0 & Moderately \\
12 & 65 & Male & Body and tail & Absent & T3N1M0 & Well \\
13 & 71 & Female & Head & Present & T2N1M0 & Poorly \\
14 & 52 & Male & Body and tail & Absent & T1N0M0 & Moderately \\
15 & 49 & Male & Body and tail & Present & T3N1M0 & Poorly \\
\hline
\end{tabular}

version 20.0 (IBM Corp., New York, NY, USA). A probability value of $\mathrm{P}<0.05$ was considered statistically significant.

\section{Results}

Differentially expressed lncRNAs in PDAC. The clinical parameters of all patients are shown in Table I. The lncRNA expression profile data from the microarray analysis contained a total of 21,558 $\mathrm{lncRNAs}$ that were expressed in PDAC tissue samples. To determine the relationships among the specimens, hierarchical clustering analysis was used to group the specimens according to their expression levels (data not shown). Volcano Plots and the scatterplot of IncRNA expression profile are useful for assessing the variation or reproducibility (Fig. 1A and B). We identified hundreds of significantly differentiated lncRNAs (fold change $\geq 2.0, \mathrm{P} \leq 0.05$ ) between 3 human PDAC tissue samples and the matched adjacent non-tumor samples. In total, there were 2,331 upregulated $\operatorname{lncRNAs}$ and 1,641 downregulated lncRNAs found in the 3 PDAC patients (Fig. 1C). Upregulated lncRNAs were more common than downregulated lncRNAs in our microarray data. Among these lncRNAs, ASHGA5P050875 (fold change, 91.4095293) was the most upregulated lncRNA, and ASHGA5P044551 (fold change, 75.9252755) was the most downregulated lncRNA.

Further analysis proceeded by classifying and stratifying the IncRNAs into subgroups. Subgroups such as antisense lncRNAs, enhancer lncRNAs and lincRNAs are thought to participate in numerous diseases such as cancers. We found 69 antisense RNAs, 82 enhancer RNAs and 147 lincRNAs were upregulated in PDAC samples, respectively, and 50 antisense RNAs, 70 enhancer RNAs and 236 lincRNAs were downregulated in the adjacent non-tumor samples, respectively (data not shown). The changes of IncRNAs subgroup between the PDAC samples and adjacent non-tumor samples play an important role in the regulation of PDAC tumor progression and we will focus on subgroup lncRNAs and their related mRNA in PDAC samples in our further study.

Differentially expressed mRNAs in PDAC. The mRNA expression profile data from the microarray analysis contained a total of 14,609 mRNAs that were expressed in the PDAC tissue samples. Volcano plots and the scatterplot of lncRNA expression profile are useful for assessing the variation or reproducibility (Fig. 2A and B). Among them, 1,676 mRNAs were significantly upregulated and $1,981 \mathrm{mRNAs}$ downregulated (fold change $\geq 2.0, \mathrm{P} \leq 0.05$ ) in the PDAC samples (Fig. 2C). The most significantly deregulated mRNAs were ASHGA5P012017 (upregulated, fold change, 89.8272773) and ASHGA5P033632 (downregulated, fold change, 463.3570246).

GO analysis. Gene Ontology (GO) analysis was performed to determine the transcripts with terms under the biological process, cellular component, and molecular function ontology in this study. Fisher's exact test was applied to find if there were more overlap between the differentially expressed list and the GO annotation list than would be expected by chance. The P-values were used to estimate the significance of GO terms enrichment in the differentially expressed lncRNAs and mRNAs; the lower the P-value, the more significant the $\mathrm{GO}$ term (P-values $\leq 0.05$ is recommended). We found that the highest enriched GO terms for the upregulated transcripts were purine nucleoside catabolic process (Fig. 3A; GO:0006152 under biological process, $\mathrm{P}=8.072 \mathrm{E}-06$ ), cytoplasm (Fig. 3B; GO:0005737 under cellular component; $\mathrm{P}=1.158 \mathrm{E}-09$ ), and protein binding (Fig. 3C; GO:0005515 under molecular function; $\mathrm{P}=1.014 \mathrm{E}-09)$. The most highly enriched GO terms targeted by the downregulated transcripts were establishment of localization (Fig. 3D, GO:0051234 under biological process; $\mathrm{P}=1.968 \mathrm{E}-05$ ), cytoplasmic part (Fig. 3E, GO:0044444 under 
A

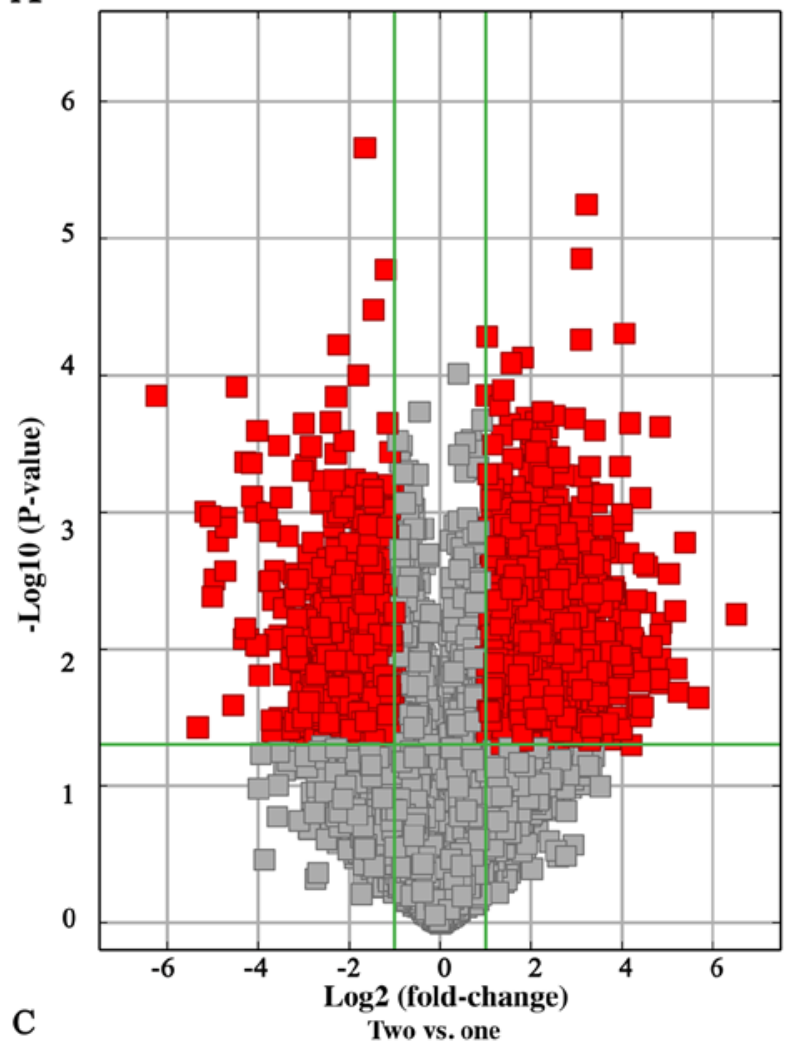

B

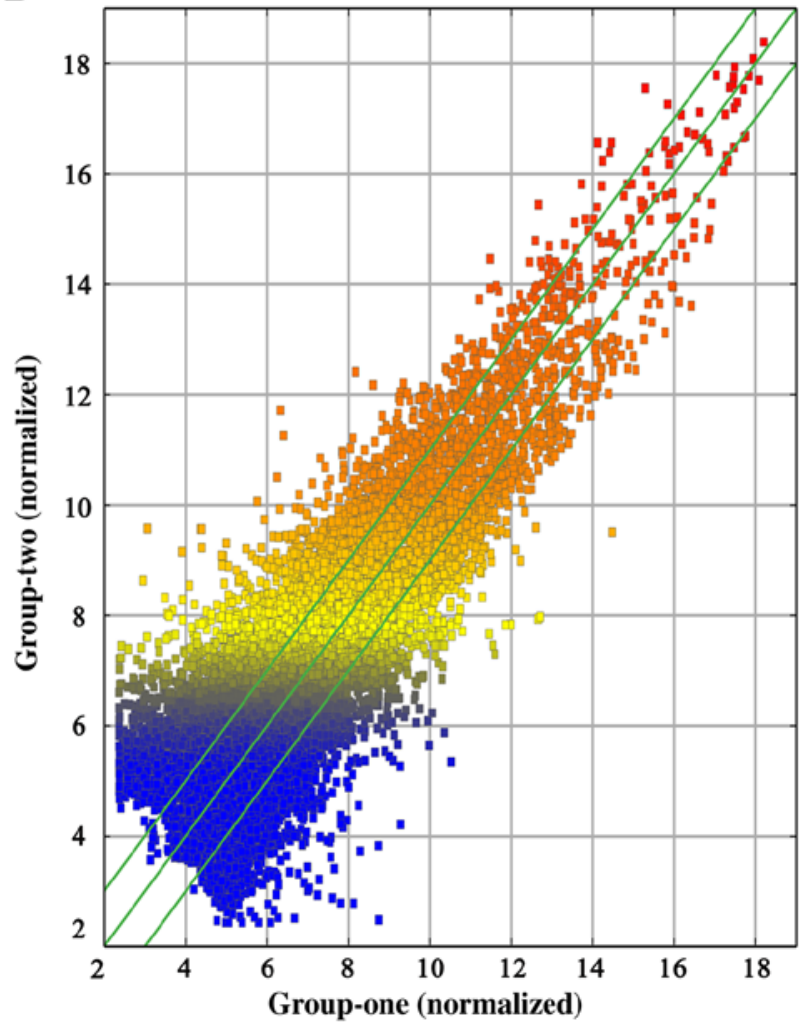

\begin{tabular}{|c|c|c|c|c|c|}
\hline \multicolumn{3}{|c|}{ Upregulated IncRNAs } & \multicolumn{3}{|c|}{ Downregulated IncRNAs } \\
\hline LncRNA seqname & $\begin{array}{l}\log _{2} \text { fold } \\
\text { change(T/N) }\end{array}$ & P-value & LncRNA seqname & $\begin{array}{c}\log _{2} \text { fold } \\
\text { change(T/N) }\end{array}$ & P-value \\
\hline NR_028050 & 91.4095293 & 0.005567934 & ENSTO0000441160 & 75.9252755 & 0.000141016 \\
\hline ENSTO0000447424 & 51.216034 & 0.022582318 & TCONS_00019731 & 40.4080819 & 0.037343693 \\
\hline uc002zis.1 & 41.8248975 & 0.00166534 & NR_045023 & 35.8997577 & 0.000991419 \\
\hline ENST00000564464 & 37.9810627 & 0.020586736 & NR_045028 & 33.151129 & 0.001070129 \\
\hline ENST00000563035 & 36.7143673 & 0.013827138 & uc002hom.1 & 32.2843834 & 0.004138791 \\
\hline NR_028308 & 36.0925624 & 0.005239717 & uc002nbr.3 & 31.3116436 & 0.003086069 \\
\hline NR_026860 & 32.6423134 & 0.002817089 & ENSTO0000492250 & 29.6902198 & 0.001626726 \\
\hline NR_024065 & 29.0228059 & 0.006449719 & NR_027170 & 26.488214 & 0.002693217 \\
\hline uc004aef.3 & 28.6639587 & 0.011700039 & ENST00000366185 & 26.2631702 & 0.001278115 \\
\hline ENST00000507636 & 28.6279164 & 0.007792702 & NR_027165 & 26.1238719 & 0.001097762 \\
\hline ENST00000555934 & 28.5138142 & 0.000238531 & ENSTO0000472494 & 23.477497 & 0.025761484 \\
\hline ENST00000559977 & 28.2364119 & 0.017772394 & NR_038940 & 22.2210271 & 0.000120804 \\
\hline NR_037856 & 27.9991637 & 0.016710478 & ENST00000437289 & 20.0259216 & 0.0083617 \\
\hline ENST00000427458 & 25.194325 & 0.009553842 & ENST00000483140 & 19.6134918 & 0.000429554 \\
\hline uc003hls. 3 & 23.5852818 & 0.002516587 & uc004dgk.1 & 19.5784842 & 0.007077379 \\
\hline ENST00000452320 & 22.67137 & 0.004580354 & ENST00000413066 & 18.7889946 & 0.008380664 \\
\hline ENST00000448636 & 22.2903469 & 0.002363901 & ENST00000420701 & 17.7344281 & 0.000438458 \\
\hline ENST00000567533 & 21.9287712 & 0.026622229 & NR_045021 & 17.607198 & 0.000764117 \\
\hline ENST00000507761 & 21.3012157 & 0.030830215 & NR_045025 & 16.9663097 & 0.000994916 \\
\hline NR_033925 & 21.1289011 & 0.0007845 & ENSTO0000472293 & 16.5440365 & 0.009320852 \\
\hline
\end{tabular}

Figure 1. (A) Volcano plots of lncRNA expression profile. The vertical lines correspond to $1.5 \mathrm{FC}$ up and down and the horizontal line represents a P-value of 0.05. (B) The scatterplot of IncRNA expression profile, which is useful for assessing the variation (or reproducibility). (C) The top 20 differentially expressed IncRNAs determined by microarray.

cellular component; $\mathrm{P}=1.394 \mathrm{E}-09)$, and protein binding

(Fig. 3F, GO:0005515 under molecular function; P=9.546E-09).
Pathway analysis. Pathway analysis indicated that 41 pathways corresponded to the upregulated transcripts (Fig. 4A). 
A

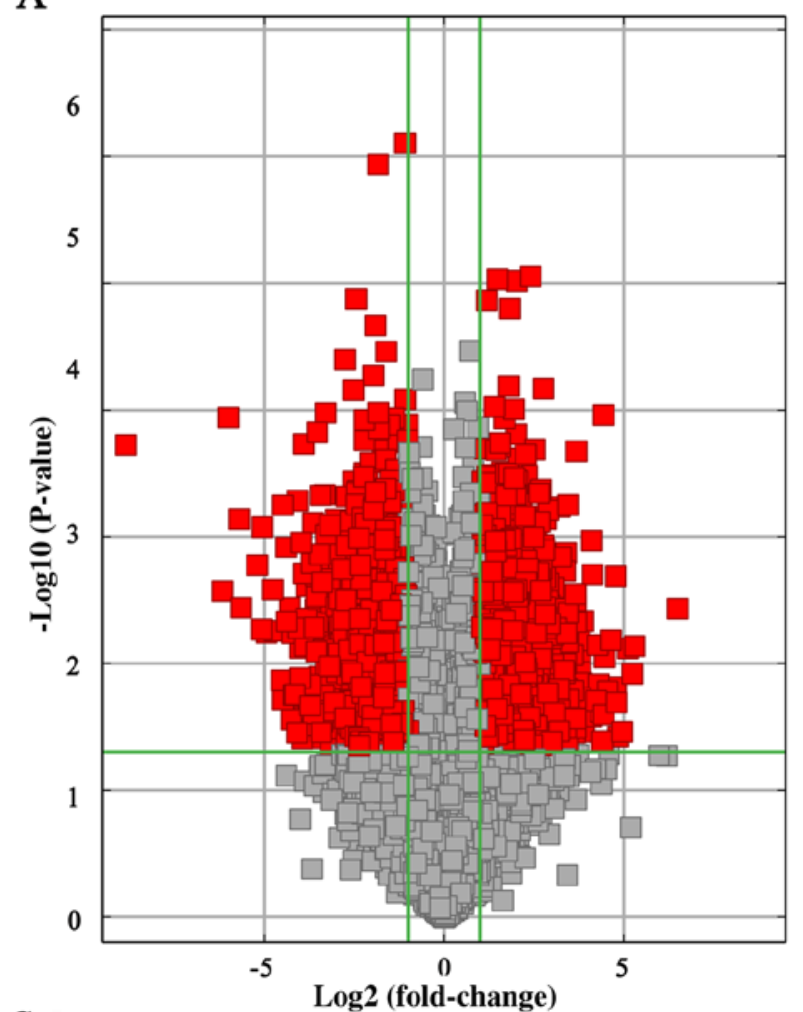

C

\begin{tabular}{|c|c|c|c|c|c|}
\hline \multicolumn{3}{|c|}{ Upregulated IncRNAs } & \multicolumn{3}{|c|}{ Down regulated IncRNAs } \\
\hline mRNA seqname & $\begin{array}{l}\log _{2} \text { fold } \\
\text { change }(T / N)\end{array}$ & P-value & mRNA seqname & $\begin{array}{l}\log _{2} \text { fold } \\
\text { change(T/N) }\end{array}$ & P-value \\
\hline NM_001161728 & 89.8272773 & 0.00370309 & ENSTO0000283752 & 463.3570246 & 0.000188295 \\
\hline NM_001135865 & 39.1999316 & 0.007228058 & NM_006761 & 71.8652785 & 0.002676106 \\
\hline NM_130464 & 37.71058 & 0.012033141 & NM_023915 & 64.1878559 & 0.000114135 \\
\hline NM_183228 & 34.3627256 & 0.007570061 & NM_014211 & 51.8000027 & 0.000722116 \\
\hline NM_019609 & 30.4993572 & 0.03460492 & NM_018011 & 50.1143222 & 0.003635692 \\
\hline NM_005110 & 28.4424059 & 0.037769752 & ENST00000372080 & 36.8932983 & 0.001672818 \\
\hline NM_212557 & 27.6440707 & 0.020302028 & NM_000096 & 33.4949904 & 0.005368147 \\
\hline NM_001039567 & 27.2912897 & 0.015366135 & NM_006815 & 33.2967101 & 0.000838544 \\
\hline NM_000088 & 27.1714597 & 0.002040782 & NM_001129828 & 30.7716315 & 0.005736589 \\
\hline NM_024697 & 24.9220171 & 0.006512799 & NM_001130716 & 27.2999531 & 0.002596408 \\
\hline ENSTO0000297307 & 23.3781203 & 0.016420116 & ENSTO0000255030 & 26.5502216 & 0.005523653 \\
\hline NM_001114395 & 21.9485861 & 0.008960227 & NM_005672 & 22.8292739 & 0.013605653 \\
\hline NM_000169 & 21.5510327 & 0.025232162 & NM_001145718 & 22.539428 & 0.000562348 \\
\hline NM_002381 & 21.5025144 & 0.000109238 & NM_004645 & 22.4669379 & 0.019047715 \\
\hline NM_002429 & 21.0519188 & 0.040629544 & NM_001006600 & 20.9951225 & 0.001202305 \\
\hline NM_001135940 & 20.1778912 & 0.023854387 & NM_013301 & 20.7773617 & 0.004618567 \\
\hline NM_012481 & 19.4723059 & 0.014513459 & NM_001040100 & 19.5799368 & 0.003618937 \\
\hline NM_012261 & 19.0331982 & 0.007128184 & NM_003400 & 19.0160782 & 0.027422151 \\
\hline NM_007281 & 18.5919201 & 0.019522239 & NM_138720 & 18.7968138 & 0.005753083 \\
\hline ENSTO0000264360 & 17.2827302 & 0.001976335 & ENST00000264218 & 18.336285 & 0.017638669 \\
\hline
\end{tabular}

B

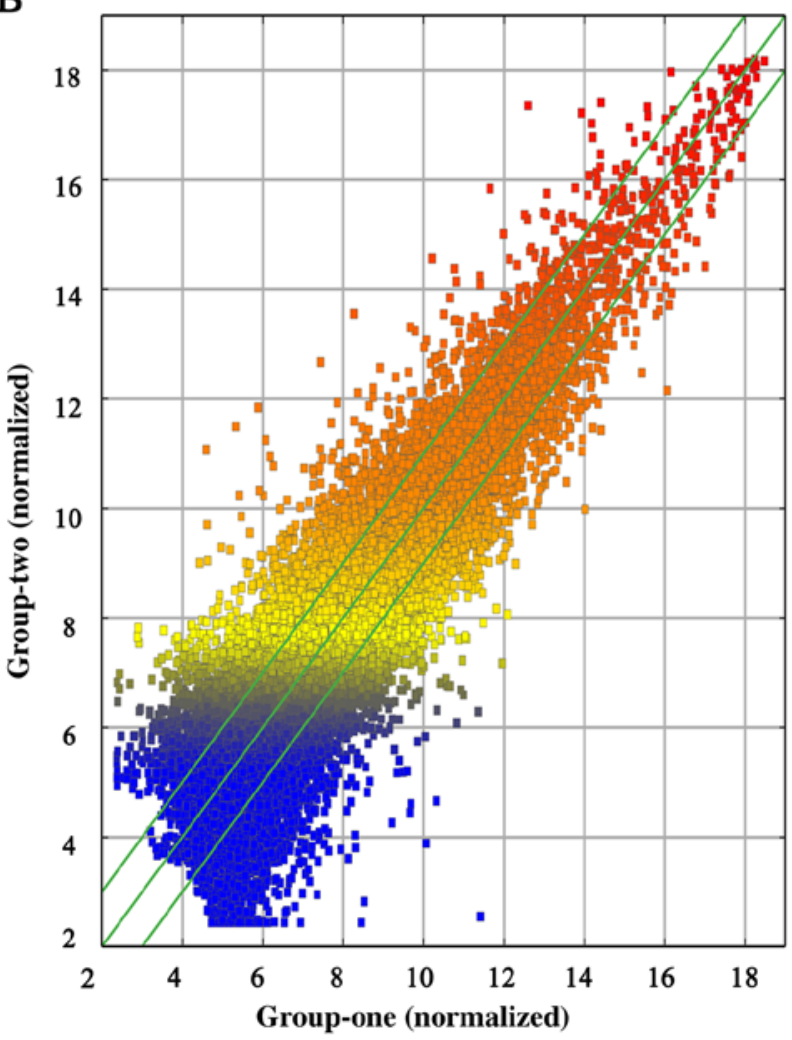

Figure 2. (A) Volcano plots of mRNA expression profile. The vertical lines correspond to $1.5 \mathrm{FC}$ up and down and the horizontal line represents a P-value of 0.05 . (B) The scatterplot of mRNA expression profile, which is useful for assessing the variation (or reproducibility). (C) The top 20 differentially expressed mRNAs determined by microarray.

The most enriched network was ' $\mathrm{B}$ cell receptor signaling pathway (human)' (Fisher P=9.08198E-06, Fig. 4C) with 18 
A

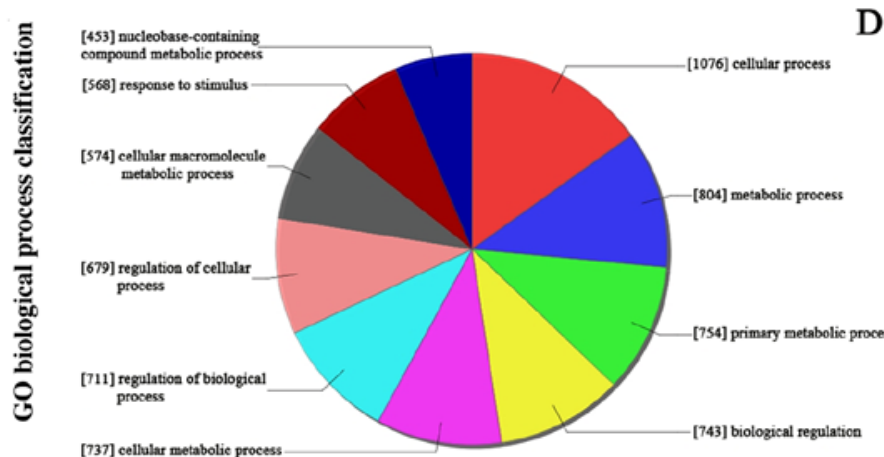

B

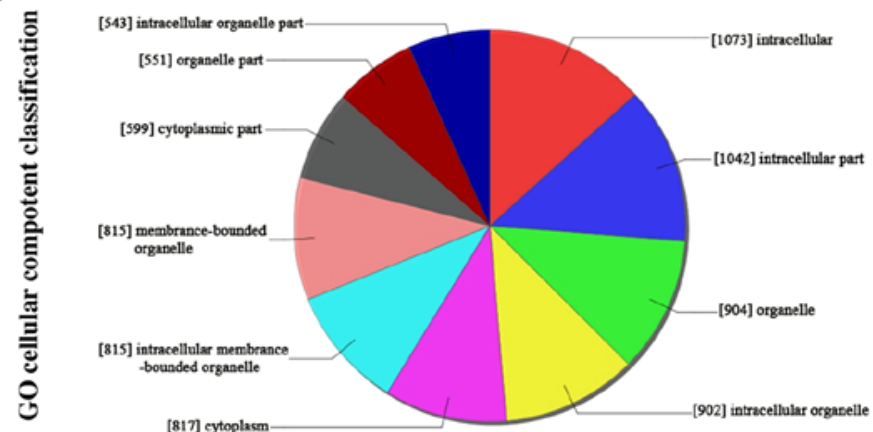

D

E
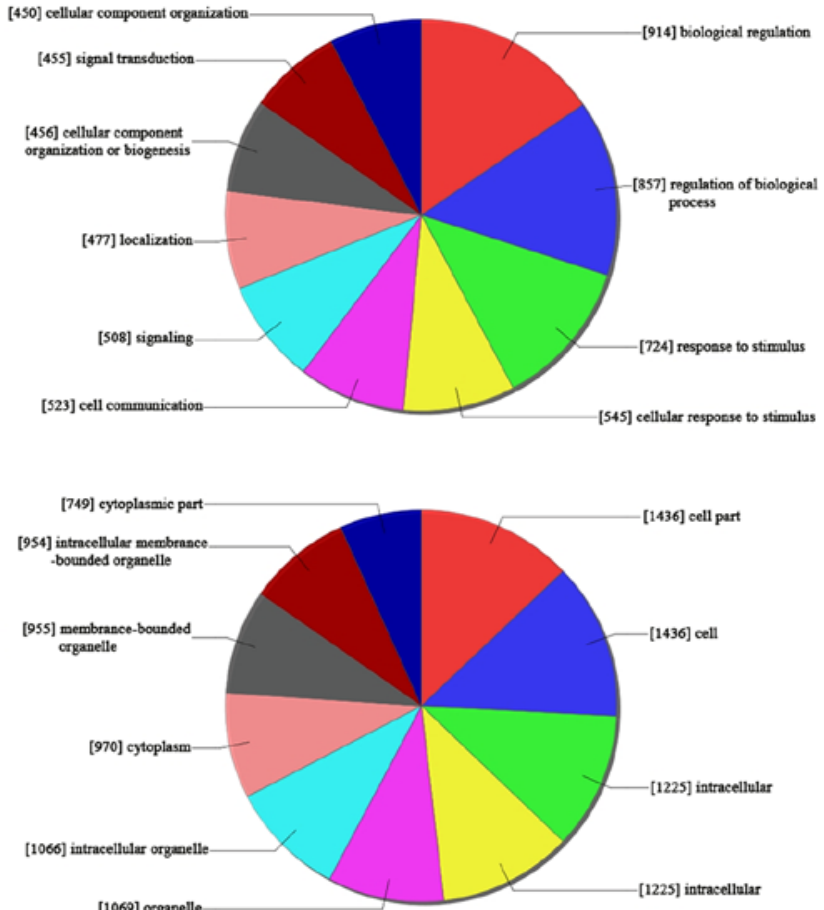

F

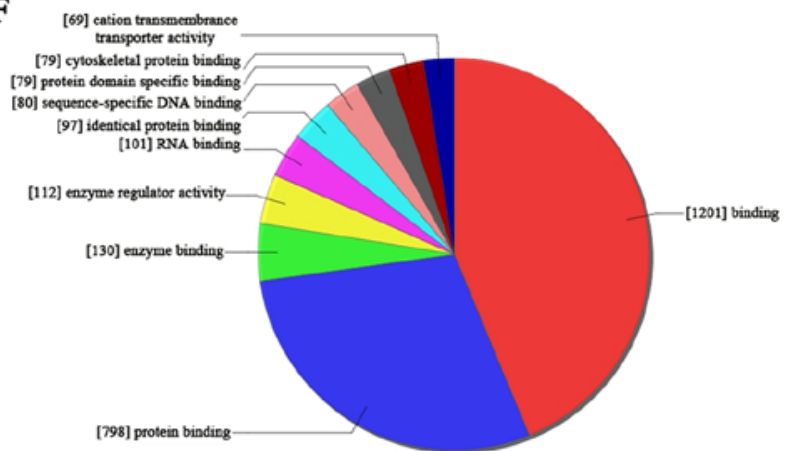

Downregulation

Figure 3. The most highly enriched GO terms for the differentially expressed transcripts. (A-C) Most highly enriched GO terms for the upregulated transcripts. (A) Biological process (BP); (B) Cellular component (CC); (C) Molecular function (MF). (D-F) Most highly enriched GO terms for downregulated transcripts: (D) Biological process (BP); (E) Cellular component (CC); (F) Molecular function (MF).

the most enriched network was 'Pertussis-Homo sapiens (human)' (Fisher $\mathrm{P}=0.0002931875$, Fig. 5) with 18 transcripts annotated with this term. P-values $\leq 0.05$ were taken as the cut-off. Among these pathways, the gene category 'Wnt signaling pathway', has been reported to be involved in metastasis of pancreatic carcinogenesis (25), and the gene category 'MAPK signaling pathway' has been shown to participate in the progression of pancreatic cancer though multiple mechanisms (26-28). The gene categories 'FoxO signaling pathway' have been reported to suppress or activate pancreatic cancer progression by different drugs or compound $(29,30)$. The gene categories 'Ubiquitin mediated proteolysis' participate in pancreatic cancer cell growth in vitro and in vivo (31).

Quantitative real-time PCR validation. We used qRT-PCR to validate the expression levels of the altered lncRNAs in the PDAC patients. We randomly selected ten upregulated
lncRNAs and five downregulated lncRNAs among the differentially expressed lncRNAs. We found that ASHGA5P022276, ASHGA5P029774, ASHGA5P028603, ASHGA5P014632, ASHGA5P043753, ASHGA5P036884, ASHGA5P016768, ASHGA5P032173, ASHGA5P051732 and ASHGA5P014130 were upregulated, and ASHGA5P055771, ASHGA5P044524, ASHGA5P039672, ASHGA5P017734 and ASHGA5P018902 were downregulated in the PDAC samples compared with adjacent non-tumor samples. Thus, the results from the qRT-PCR analysis and the microarray data analysis were consistent $(\mathrm{P}<0.05$; Fig. $6 \mathrm{~A}$ and $\mathrm{B})$.

Moreover, we found a significant increase of the expression level of HOTAIRM1 (fold change, 6.9263288, $\mathrm{P}=0.00282$ ) in PDAC samples compared with adjacent non-tumor samples via microarray analysis. To examine whether upregulated expression of HOTAIRM1 is pathologically specific, a total of 12 PDAC samples and matched adjacent non-tumor samples 
A

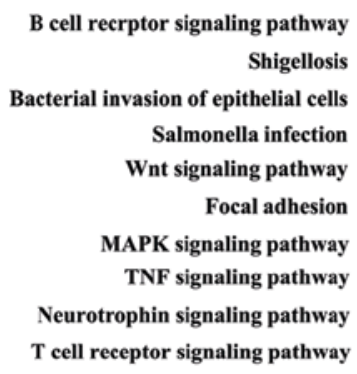

B cell recrptor signaling pathway

Shigellosis

Bacterial invasion of epithelial cells Salmonella infection Wnt signaling pathway Focal adhesion

MAPK signaling pathway

TNF signaling pathway

Neurotrophin signaling pathway

T cell receptor signaling pathway

Sig pathway of DE gene

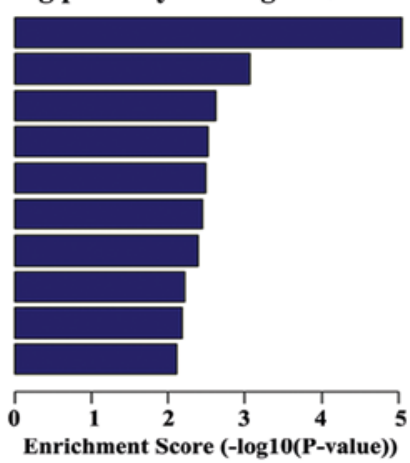

B

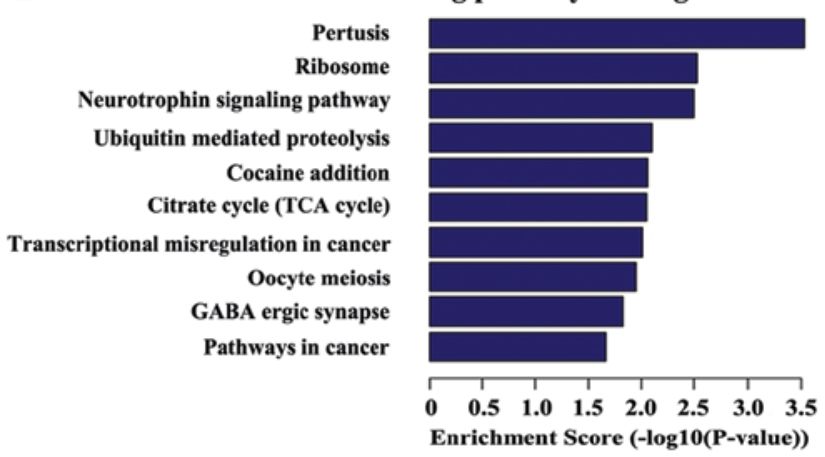

C

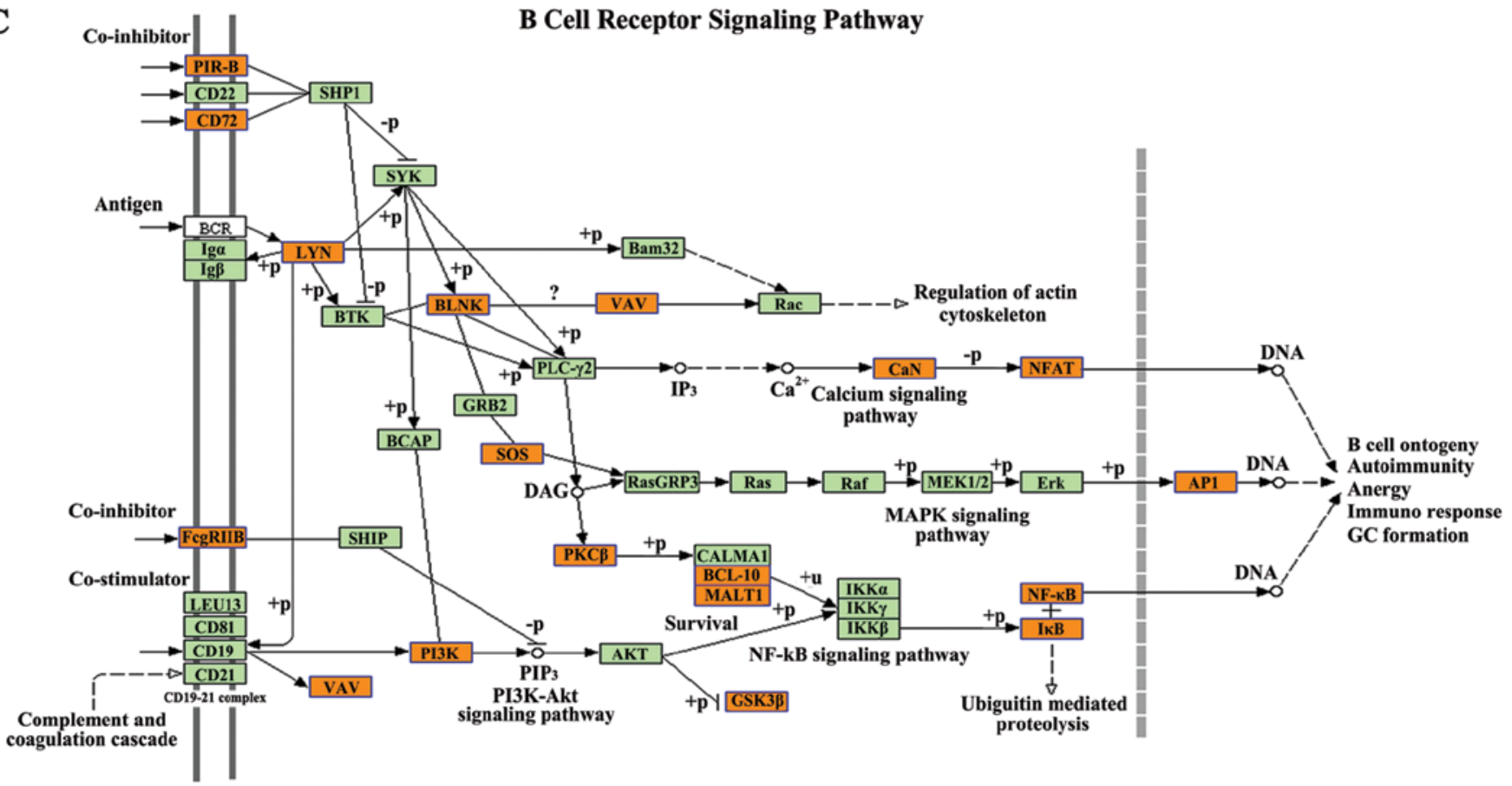

Figure 4. Pathway analysis for the differentially expressed transcripts and schematic diagrams of two gene categories. (A) Pathways corresponding to the upregulated transcripts. (B) Pathways corresponding to downregulated transcripts. (C) Schematic diagram of the gene category 'B cell receptor-signaling pathway'.

were subjected to qRT-PCR. The level of HOTAIRM1 expression was 2.92-8.53-fold higher in PDAC samples than the mean level in matched adjacent non-tumor samples (Fig. 6C). However, the sample size of this study is limited and we will further collect more samples and investigate the function of HOTAIRM1 in PDAC.

\section{Discussion}

In this study, we used a microarray to test the lncRNAs expression profiles in PDAC tissues. The lncRNA expression profiling data showed that there were IncRNAs that were differentially expressed between the PDAC tissues and matched adjacent non-tumor tissues. Previous studies showed that dysregulation of lncRNAs expression such as HOTAIR $(32,33)$, HULC (34-36) and GAS5 (37,38), is a potential molecular marker for diagnostic and therapeutic purposes in several human cancers. There are still lncRNAs as potential novel candidate molecular markers for clinical diagnosis and therapy of PDAC that need to be further identified.
Although special lncRNAs as molecular markers in other digestive tumors, such as hepatocellular carcinoma and gastric cancer $(39,40)$ have been reported, there is no direct evidence shown that special lncRNAs are molecular markers for PDAC. Moreover, several IncRNAs have been reported to be significantly correlated with PDAC outcome and are involved in cancer progression. HOTAIR is a negative prognostic factor for breast, colon and liver cancer patient survival, and increased HOTAIR expression in patients has been correlated with enhanced breast and colon cancer metastasis (41-45). Kyounghyun et al (46) showed that HOTAIR expression was increased markedly in pancreatic tumors compared to non-tumor tissues, and was associated with more aggressive tumors. MALAT1 $(47,48)$, also known as nuclear-enriched abundant transcript 2 (NEAT2), regulates gene expression and post-transcriptionally modifies primary transcripts and is found to be upregulated in a variety of human cancers of the breast, prostate, colon, liver, and uterus (49). Recently, MALAT1 mRNA level was found significantly higher in PADC tissues and some PC cell lines. A high expression of MALAT1 was detected in PDAC tumors 


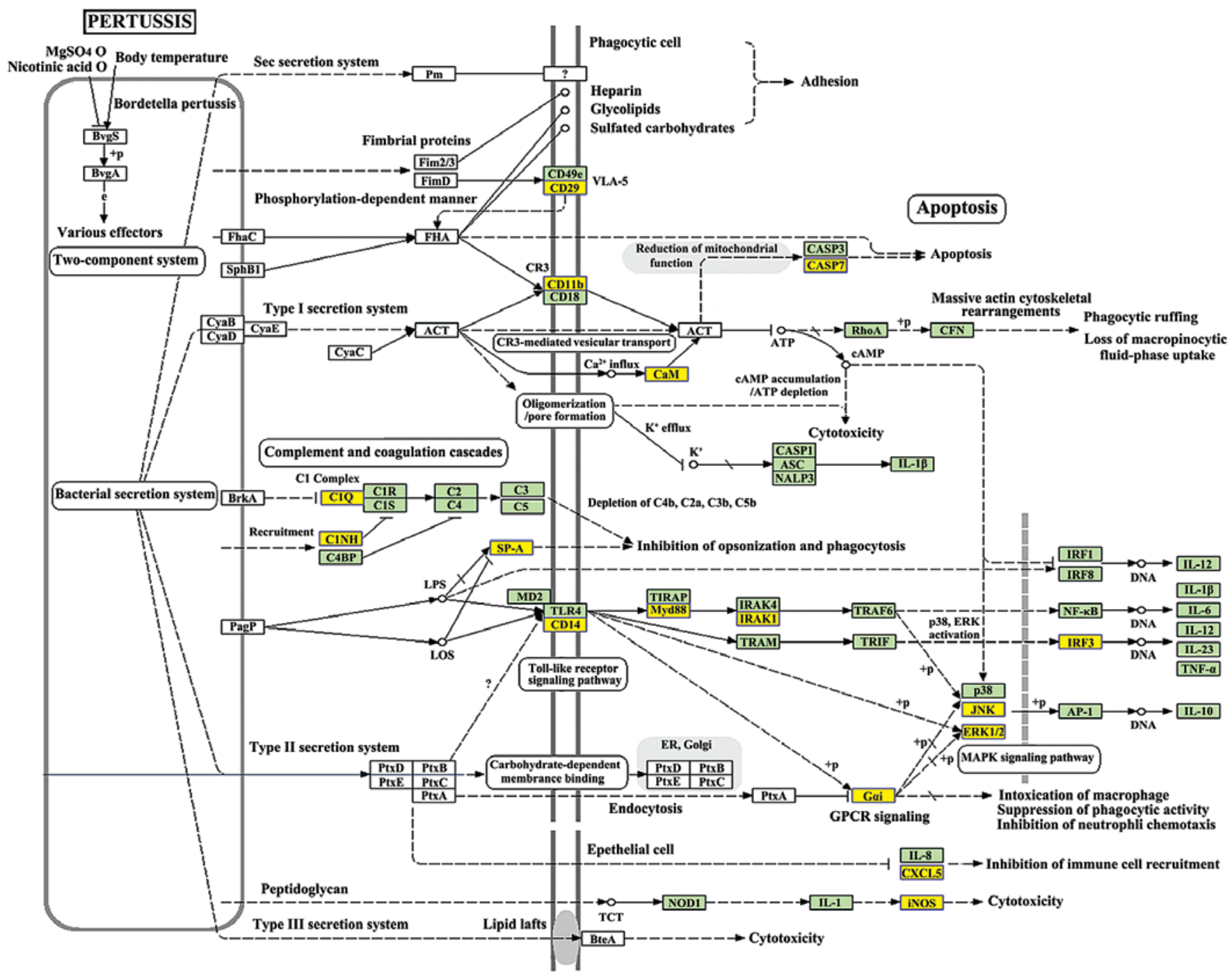

Figure 5. Schematic diagram of the gene category 'Pertussis-Homo sapiens".

of larger size, advanced tumor stage and deeper invasion. In addition, the overexpression of MALAT1 was associated with poor prognosis of PDAC patients (50). The HOTTIP IncRNA, located at the 5'-end of the HOXA cluster, was significantly expressed in anatomically distal human fibroblasts (51). Recent study demonstrates that HOTTIP, which is significantly overexpressed in PDAC, plays a significant role in PDAC progression and gemcitabine chemoresistance (52). H19 was characterized as an oncogenic lncRNA in some tumors and upregulated remarkably in primary PDAC tumors that subsequently metastasized, compared to those with non-metastasis. H19 also promoted PDAC cell invasion and migration at least partially by increasing HMGA2mediated epithelial-mesenchymal transition (EMT) through antagonizing let-7 (53). The previous studies also reported several other lncRNAs related to PDAC, such as HULC, PVTI, MAP3K14, PPP3Cb, DAPKI and LOC285194 (54-57). In the present study, we also examined the expression of some most studied lncRNAs in PDAC, such as MALAT1, HOTTIP, H19, HULC, PVTI, MAP3K14, PPP3Cb, DAPKI and LOC285194 in the combination data set of 3 pairs of microarrays, showing that MALAT1 and HOTTIP were significantly upregulated 16.22- and 23.48-fold in PDAC tissues compared with paired non-tumor tissues respectively; however, other IncRNAs were not significantly differentially expressed between PDAC tissues and paired non-tumor tissues.

The microarray expression profiles revealed 21,558 lncRNAs that were expressed in those samples; 2,331 lncRNAs were significantly upregulated and 1,641 lncRNAs were significantly downregulated in 3 PDAC samples compared with the paired non-tumor tissues. We then randomly selected 14 IncRNAs for validation by qRT-PCR in other 12 PDAC samples and paired non-tumor tissues. Additionally, the results from the qRT-PCR analysis and the microarray data analysis were consistent. In these deregulated lncRNAs, we then analyzed the subgroup lncRNAs, including the antisense lncRNAs, the enhancer lncRNAs and the lincRNAs, and their related mRNA that may play an important role in the regulation mechanism of PDAC progression. Antisense lncRNAs have been recognized to regulate expression of corresponding coding genes at post-transcriptional level (58), and therefore 

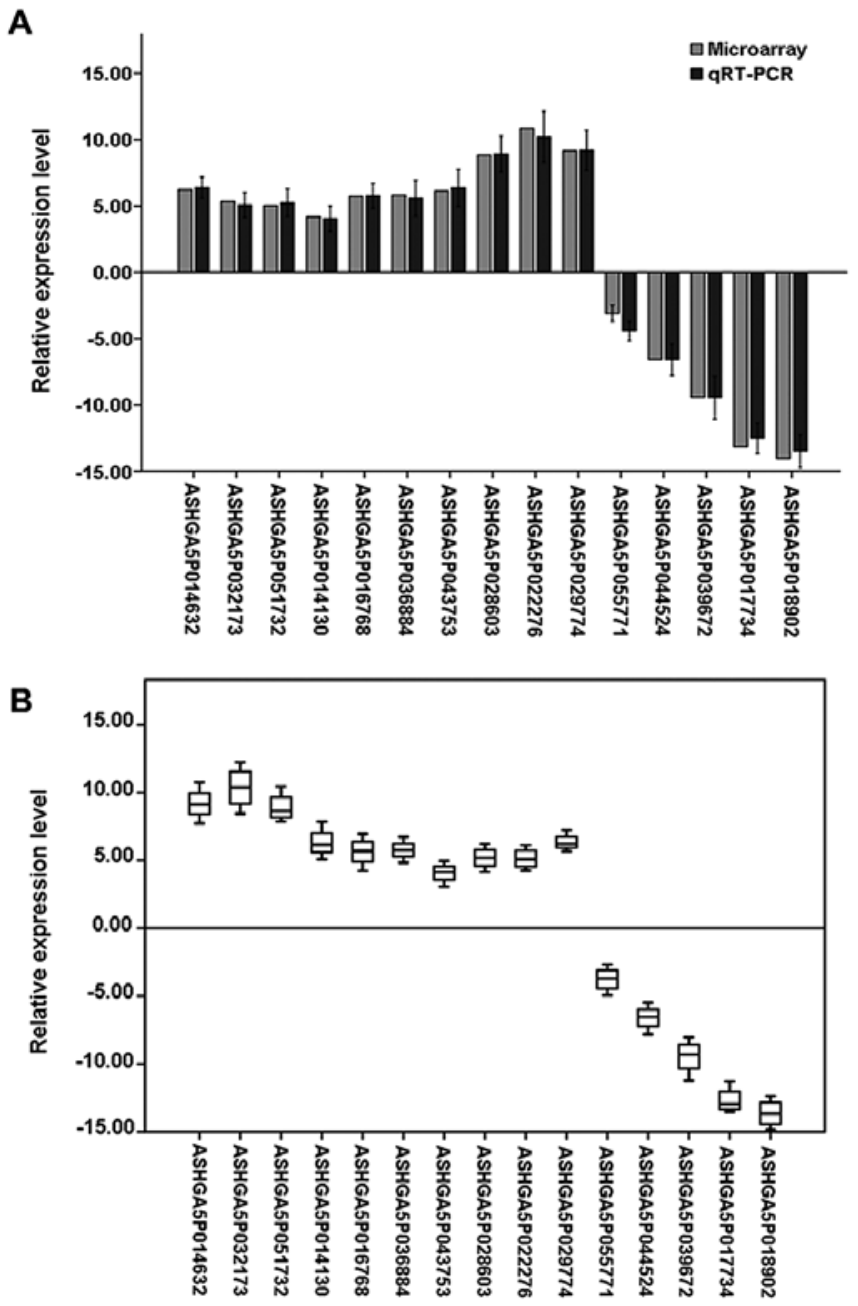

C

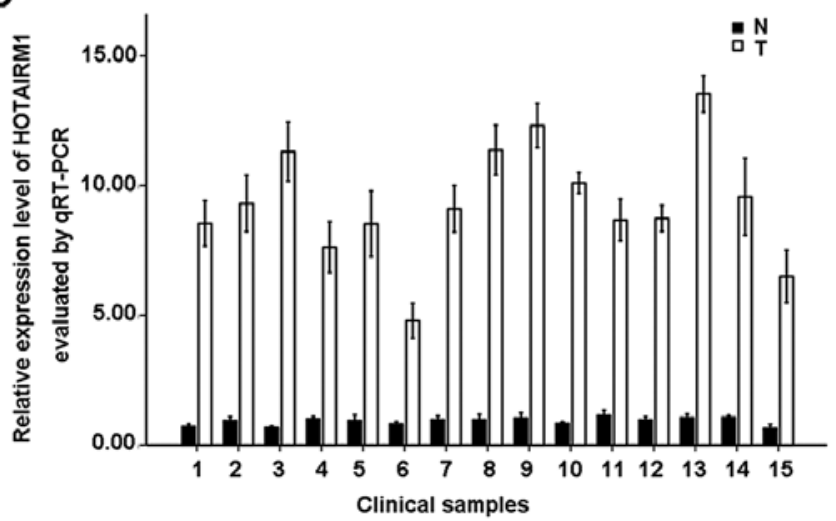

Figure 6. Comparison and distributions of lncRNAs expression levels between the microarray and qRT-PCR results. (A) Comparison of the expression levels of 1 ncRNAs. Fifteen differentially expressed lncRNAs were validated by qRT-PCR. The Y-axis represents the log-transformed median fold changes $(\mathrm{T} / \mathrm{N})$ in expression across 15 samples $(\mathrm{P}<0.05)$. The qRT-PCR results were consistent with the microarray data. (B) Distributions of IncRNAs expression levels $(\mathrm{P}<0.05)$. Fifteen differentially expressed $\operatorname{lncRNAs}$ were validated by qRT-PCR in 12 PDAC and paired non-tumor tissue samples. (C) Relative expression levels of HOTAIRM1 evaluated by qRT-PCR in 15 PDAC and paired non-tumor tissue samples.

participate in carcinogenesis by regulation of oncogenes as well as anti-oncogenes. Enhancer RNAs are required for efficient transcriptional enhancement of interacting target genes and also are required for p53-dependent enhancer activity and gene transcription (59-62). LincRNAs play pivotal roles in cancer-related gene regulatory system, and the disorder of their gene expression is thought to promote cancer cell proliferation, invasion and metastasis (63-67). In the present study, our data showed that 69 antisense RNAs, 82 enhancer RNAs and 147 lincRNAs were upregulated in PDAC tissues, and 50 antisense RNAs, 70 enhancer RNAs and 236 lincRNAs were downregulated in adjacent non-tumor tissues. In our additional study, we focused on the function and regulation mechanism of the interesting subgroup lncRNAs in PDAC progression.

We performed GO and pathway analyses to predict the biological functions and potential mechanisms of the differentially expressed lncRNAs in PDAC progression. In this study, we found that the highest enriched GO terms for the upregulated transcripts were purine nucleoside catabolic process, cytoplasm, and protein binding and the most highly enriched GO terms targeted by the downregulated transcripts were establishment of localization, cytoplasmic part, and protein binding. The GO project is a collaborative effort that addresses the need for consistent descriptions of gene products in terms of their 'biology' in a species-independent manner (68). To gain insight into the underlying biology of the differentially expressed transcripts, we performed pathway analysis and found that the upregulated transcripts were associated with 41 pathways; the downregulated transcripts were associated with 25 pathways. Among these pathways, the gene category 'B cell receptor signaling pathway (human)' is involved in the initiation and growth of human pancreatic ductal adenocarcinoma (69). The gene category Wnt signaling pathway, has been reported to be involved in metastasis of pancreatic carcinogenesis (25), and the gene category MAPK signaling pathway has been shown to participate in the progression of pancreatic cancer though multiple mechanisms (26-28,70). The gene categories FoxO signaling pathway have been reported to suppress or activate pancreatic cancer progression by different drugs or compound $(29,30)$. The gene categories 'Ubiquitin mediated proteolysis' participates in pancreatic cancer cell growth in vitro and in vivo (31). The result of pathway analysis using bioinformatics to find the specific regulation mechanisms in PDAC progression is important for our further studies.

Moreover, we found a significant increase of the expression level of HOTAIRM1 in PDAC samples comparing with the non-tumor tissues via microarray analysis. To examine whether the upregulated expression of HOTAIRM1 is pathologically specific, a total of 12 PDAC samples and paired non-tumor tissues were subjected to qRT-PCR. HOTAIRM1 expression level was higher in PDAC samples than the mean level in paired non-tumor tissues. HOTAIRM1 is a long intergenic non-coding RNA located at the 3'-end of the HOXA cluster, upregulated during myeloid maturation (71). HOTAIRM1 may affect cell fate by regulating cell cycle progression and serving as a link in the coordinated regulation of an extensive gene expression program. Although, the expression of HOTAIRM1 was previously shown to be specific to the myeloid lineage of hematopoietic cells (72), a recent study reported that the HOTAIRM1 was overexpressed in the basal-like subtype of breast cancer (73). Together with our present study in PDAC tissues by microarray and qRT-PCR, the long intergenic noncoding RNA HOTAIRM1 may participate in the development 
and progression of several cancers. Thus, further studies are needed to clarify its role in the regulation effect of PDAC.

This study revealed differential expression patterns of lncRNAs in 3 PDAC patients, in which 2,331 upregulated and 1,641 downregulated lncRNAs were found in PDAC tissues relative to paired non-tumor tissues. In addition, the study helped us to understand the potential mechanisms of the carcinogenesis of PDAC preliminarily through 'GO' analysis, signaling pathway analysis and lncRNA classification analysis. Furthermore, this study is the first on the long intergenic noncoding RNA HOTAIRM1 in PDAC, which may be used as a molecular marker in the future to predict response to treatment as well as patient outcome of PDAC.

\section{Acknowledgements}

The authors thank all the patients who participated in this study. This study was supported by grants from the Natural Science Foundation of China (no. 81271007).

\section{References}

1. Kazanjian KK, Hines OJ, Duffy JP, Yoon DY, Cortina G and Reber HA: Improved survival following pancreaticoduodenectomy to treat adenocarcinoma of the pancreas: The influence of operative blood loss. Arch Surg 143: 1166-1171, 2008

2. Oettle H, Neuhaus P, Hochhaus A, Hartmann JT, Gellert K, Ridwelski K, Niedergethmann M, Zülke C, Fahlke J, Arning MB, et al: Adjuvant chemotherapy with gemcitabine and long-term outcomes among patients with resected pancreatic cancer: The CONKO-001 randomized trial. JAMA 310 1473-1481, 2013

3. Yang J, Li J, Zhu R, Zhang H, Zheng Y, Dai W, Wang F, Shen M, Chen K, Cheng P, et al: K-ras mutational status in cytohistological tissue as a molecular marker for the diagnosis of pancreatic cancer: A systematic review and meta-analysis. Dis Markers 2014: 573783, 2014.

4. Cowan RW and Maitra A: Genetic progression of pancreatic cancer. Cancer J 20: 80-84, 2014.

5. Dempe S, Stroh-Dege AY, Schwarz E, Rommelaere J and Dinsart C: SMAD4: A predictive marker of PDAC cell permissiveness for oncolytic infection with parvovirus $\mathrm{H}-1 \mathrm{PV}$. Int $\mathbf{J}$ Cancer 126: 2914-2927, 2010.

6. Lu J, Getz G, Miska EA, Alvarez-Saavedra E, Lamb J, Peck D, Sweet-Cordero A, Ebert BL, Mak RH, Ferrando AA, et al: MicroRNA expression profiles classify human cancers. Nature 435: 834-838, 2005.

7. Ho AS, Huang X, Cao H, Christman-Skieller C, Bennewith K, Le QT and Koong AC: Circulating miR-210 as a novel hypoxia marker in pancreatic cancer. Transl Oncol 3: 109-113, 2010.

8. Kawaguchi T, Komatsu S, Ichikawa D, Morimura R, Tsujiura M, Konishi H, Takeshita H, Nagata H, Arita T, Hirajima S, et al: Clinical impact of circulating miR-221 in plasma of patients with pancreatic cancer. Br J Cancer 108: 361-369, 2013.

9. Ponting CP, Oliver PL and Reik W: Evolution and functions of long noncoding RNAs. Cell 136: 629-641, 2009.

10. Tay Y, Karreth FA and Pandolfi PP: Aberrant ceRNA activity drives lung cancer. Cell Res 24: 259-260, 2014.

11. Salmena L, Poliseno L, Tay Y, Kats L and Pandolfi PP: A ceRNA hypothesis: The Rosetta Stone of a hidden RNA language? Cell 146: 353-358, 2011.

12. Beroukhim R, Mermel CH, Porter D, Wei G, Raychaudhuri S, Donovan J, Barretina J, Boehm JS, Dobson J, Urashima M, et al: The landscape of somatic copy-number alteration across human cancers. Nature 463: 899-905, 2010.

13. Futreal PA, Coin L, Marshall M, Down T, Hubbard T, Wooster R, Rahman N and Stratton MR: A census of human cancer genes. Nat Rev Cancer 4: 177-183, 2004.

14. Stratton MR, Campbell PJ and Futreal PA: The cancer genome. Nature 458: 719-724, 2009.

15. Nagano $T$ and Fraser P: No-nonsense functions for long noncoding RNAs. Cell 145: 178-181, 2011.
16. Flynn RA and Chang HY: Active chromatin and noncoding RNAs: An intimate relationship. Curr Opin Genet Dev 22: 172-178, 2012.

17. Kung JT, Colognori D and Lee JT: Long noncoding RNAs: Past, present, and future. Genetics 193: 651-669, 2013.

18. Hung T and Chang HY: Long noncoding RNA in genome regulation: Prospects and mechanisms. RNA Biol 7: 582-585, 2010.

19. Mercer TR, Dinger ME and Mattick JS: Long non-coding RNAs: Insights into functions. Nat Rev Genet 10: 155-159, 2009.

20. Jiang J, Jing Y, Cost GJ, Chiang JC, Kolpa HJ, Cotton AM, Carone DM, Carone BR, Shivak DA, Guschin DY, et al: Translating dosage compensation to trisomy 21. Nature 500: 296-300, 2013

21. Yildirim E, Kirby JE, Brown DE, Mercier FE, Sadreyev RI, Scadden DT and Lee JT: Xist RNA is a potent suppressor of hematologic cancer in mice. Cell 152: 727-742, 2013.

22. Hajjari M and Salavaty A: HOTAIR: An oncogenic long noncoding RNA in different cancers. Cancer Biol Med 12: 1-9, 2015.

23. Pang EJ, Yang R, Fu XB and Liu YF: Overexpression of long non-coding RNA MALAT1 is correlated with clinical progression and unfavorable prognosis in pancreatic cancer. Tumour Biol 36: 2403-2407, 2015

24. Ding C, Yang Z, Lv Z, Du C, Xiao H, Peng C, Cheng S, Xie H, Zhou L, Wu J, et al: Long non-coding RNA PVT1 is associated with tumor progression and predicts recurrence in hepatocellular carcinoma patients. Oncol Lett 9: 955-963, 2015.

25. Yu M, Ting DT, Stott SL, Wittner BS, Ozsolak F, Paul S, Ciciliano JC, Smas ME, Winokur D, Gilman AJ, et al: RNA sequencing of pancreatic circulating tumour cells implicates WNT signalling in metastasis. Nature 487: 510-513, 2012.

26. Miyabayashi K, Ijichi H, Mohri D, Tada M, Yamamoto K, Asaoka Y, Ikenoue T, Tateishi K, Nakai Y, Isayama $\mathrm{H}$, et al: Erlotinib prolongs survival in pancreatic cancer by blocking gemcitabine-induced MAPK signals. Cancer Res 73: 2221-2234, 2013.

27. Jun S, Lee S, Kim HC, Ng C, Schneider AM, Ji H, Ying H, Wang H, DePinho RA and Park JI: PAF-mediated MAPK signaling hyperactivation via LAMTOR3 induces pancreatic tumorigenesis. Cell Rep 5: 314-322, 2013.

28. Zhang Y, Yan W, Collins MA, Bednar F, Rakshit S, Zetter BR, Stanger BZ, Chung I, Rhim AD and di Magliano MP: Interleukin- 6 is required for pancreatic cancer progression by promoting MAPK signaling activation and oxidative stress resistance. Cancer Res 73: 6359-6374, 2013.

29. Boreddy SR, Pramanik KC and Srivastava SK: Pancreatic tumor suppression by benzyl isothiocyanate is associated with inhibition of PI3K/AKT/FOXO pathway. Clin Cancer Res 17: 1784-1795, 2011.

30. Roy SK, Chen Q, Fu J, Shankar S and Srivastava RK: Resveratrol inhibits growth of orthotopic pancreatic tumors through activation of FOXO transcription factors. PLoS One 6: e25166, 2011.

31. Ma Y, Gu Y, Zhang Q, Han Y, Yu S, Lu Z and Chen J: Targeted degradation of KRAS by an engineered ubiquitin ligase suppresses pancreatic cancer cell growth in vitro and in vivo. Mol Cancer Ther 12: 286-294, 2013.

32. Hajjari M and Khoshnevisan A: Potential long non-coding RNAs to be considered as biomarkers or therapeutic targets in gastric cancer. Front Genet 4: 210, 2013.

33. Huang L, Liao LM, Liu AW, Wu JB, Cheng XL, Lin JX and Zheng M: Overexpression of long noncoding RNA HOTAIR predicts a poor prognosis in patients with cervical cancer. Arch Gynecol Obstet 290: 717-723, 2014.

34. Panzitt K, Tschernatsch MM, Guelly C, Moustafa T, Stradner M, Strohmaier HM, Buck CR, Denk H, Schroeder R, Trauner M, et al: Characterization of HULC, a novel gene with striking up-regulation in hepatocellular carcinoma, as noncoding RNA. Gastroenterology 132: 330-342, 2007.

35. Matouk IJ, Abbasi I, Hochberg A, Galun E, Dweik H and Akkawi M: Highly upregulated in liver cancer noncoding RNA is overexpressed in hepatic colorectal metastasis. Eur J Gastroenterol Hepatol 21: 688-692, 2009.

36. Liu Y, Pan S, Liu L, Zhai X, Liu J, Wen J, Zhang Y, Chen J, Shen H and $\mathrm{Hu} \mathrm{Z}$ : A genetic variant in long non-coding RNA HULC contributes to risk of HBV-related hepatocellular carcinoma in a Chinese population. PLoS One 7: e35145, 2012.

37. Sun M, Jin FY, Xia R, Kong R, Li JH, Xu TP, Liu YW, Zhang EB, Liu XH and De W: Decreased expression of long noncoding RNA GAS5 indicates a poor prognosis and promotes cell proliferation in gastric cancer. BMC Cancer 14: 319, 2014. 
38. Renganathan A, Kresoja-Rakic J, Echeverry N, Ziltener G, Vrugt B, Opitz I, Stahel RA and Felley-Bosco E: GAS5 long noncoding RNA in malignant pleural mesothelioma. Mol Cancer 13: $119,2014$.

39. Arita T, Ichikawa D, Konishi H, Komatsu S, Shiozaki A, Shoda K, Kawaguchi T, Hirajima S, Nagata H, Kubota T, et al: Circulating long non-coding RNAs in plasma of patients with gastric cancer. Anticancer Res 33: 3185-3193, 2013.

40. Xie H, Ma H and Zhou D: Plasma HULC as a promising novel biomarker for the detection of hepatocellular carcinoma. BioMed Res Int 2013: 136106, 2013.

41. Rinn JL, Kertesz M, Wang JK, Squazzo SL, Xu X, Brugmann SA, Goodnough LH, Helms JA, Farnham PJ, Segal E, et al: Functional demarcation of active and silent chromatin domains in human HOX loci by noncoding RNAs. Cell 129: 1311-1323, 2007.

42. Gupta RA, Shah N, Wang KC, Kim J, Horlings HM, Wong DJ, Tsai MC, Hung T, Argani P, Rinn JL, et al: Long non-coding RNA HOTAIR reprograms chromatin state to promote cancer metastasis. Nature 464: 1071-1076, 2010.

43. Tsai MC, Manor O, Wan Y, Mosammaparast N, Wang JK, Lan F, Shi Y, Segal E and Chang HY: Long noncoding RNA as modular scaffold of histone modification complexes. Science 329: 689-693, 2010

44. Yang Z, Zhou L, Wu LM, Lai MC, Xie HY, Zhang F and Zheng SS: Overexpression of long non-coding RNA HOTAIR predicts tumor recurrence in hepatocellular carcinoma patients following liver transplantation. Ann Surg Oncol 18: 1243-1250, 2011.

45. Kogo R, Shimamura T, Mimori K, Kawahara K, Imoto S, Sudo T, Tanaka F, Shibata K, Suzuki A, Komune S, et al: Long noncoding RNA HOTAIR regulates polycomb-dependent chromatin modification and is associated with poor prognosis in colorectal cancers. Cancer Res 71: 6320-6326, 2011.

46. Kim K, Jutooru I, Chadalapaka G, Johnson G, Frank J, Burghardt R, Kim S and Safe S: HOTAIR is a negative prognostic factor and exhibits pro-oncogenic activity in pancreatic cancer. Oncogene 32: 1616-1625, 2013.

47. Lin R, Maeda S, Liu C, Karin M and Edgington TS: A large noncoding RNA is a marker for murine hepatocellular carcinomas and a spectrum of human carcinomas. Oncogene 26 : 851-858, 2007.

48. Ji P, Diederichs S, Wang W, Böing S, Metzger R, Schneider PM, Tidow N, Brandt B, Buerger H, Bulk E, et al: MALAT-1, a novel noncoding RNA, and thymosin beta4 predict metastasis and survival in early-stage non-small cell lung cancer. Oncogene 22 8031-8041, 2003.

49. Schorderet $P$ and Duboule D: Structural and functional differences in the long non-coding RNA hotair in mouse and human PLoS Genet 7: e1002071, 2011.

50. Liu JH, Chen G, Dang YW, Li CJ and Luo DZ: Expression and prognostic significance of lncRNA MALAT1 in pancreatic cancer tissues. Asian Pac J Cancer Prev 15: 2971-2977, 2014.

51. Wang KC, Yang YW, Liu B, Sanyal A, Corces-Zimmerman R, Chen Y, Lajoie BR, Protacio A, Flynn RA, Gupta RA, et al: A long noncoding RNA maintains active chromatin to coordinate homeotic gene expression. Nature 472: 120-124, 2011.

52. Li Z, Zhao X, Zhou Y, Liu Y, Zhou Q, Ye H, Wang Y, Zeng J, Song Y, Gao W, et al: The long non-coding RNA HOTTIP promotes progression and gemcitabine resistance by regulating HOXA13 in pancreatic cancer. J Transl Med 13: 84, 2015.

53. Ma C, Nong K, Zhu H, Wang W, Huang X, Yuan Z and Ai K: H19 promotes pancreatic cancer metastasis by derepressing let-7's suppression on its target HMGA2-mediated EMT. Tumour Biol 35: 9163-9169, 2014

54. Peng W, Gao W and Feng J: Long noncoding RNA HULC is a novel biomarker of poor prognosis in patients with pancreatic cancer. Med Oncol 31: 346, 2014.

55. You L, Chang D, Du HZ and Zhao YP: Genome-wide screen identifies PVT1 as a regulator of Gemcitabine sensitivity in human pancreatic cancer cells. Biochem Biophys Res Commun 407: 1-6, 2011.
56. Tahira AC, Kubrusly MS, Faria MF, Dazzani B, Fonseca RS, Maracaja-Coutinho V, Verjovski-Almeida S, Machado MC and Reis EM: Long noncoding intronic RNAs are differentially expressed in primary and metastatic pancreatic cancer. Mol Cancer 10: 141, 2011.

57. Ding YC, Yu W, Ma C, Wang Q, Huang CS and Huang T: Expression of long non-coding RNA LOC285194 and its prognostic significance in human pancreatic ductal adenocarcinoma. Int J Clin Exp Pathol 7: 8065-8070, 2014

58. Katayama S, Tomaru Y, Kasukawa T, Waki K, Nakanishi M, Nakamura M, Nishida H, Yap CC, Suzuki M, Kawai J, et al; FANTOM Consortium: Antisense transcription in the mammalian transcriptome. Science 309: 1564-1566, 2005.

59. Wang D, Garcia-Bassets I, Benner C, Li W, Su X, Zhou Y, Qiu J, Liu W, Kaikkonen MU, Ohgi KA, et al: Reprogramming transcription by distinct classes of enhancers functionally defined by eRNA. Nature 474: 390-394, 2011.

60. Li W, Notani D, Ma Q, Tanasa B, Nunez E, Chen AY, Merkurjev D, Zhang J, Ohgi K, Song X, et al: Functional roles of enhancer RNAs for oestrogen-dependent transcriptional activation. Nature 498: 516-520, 2013.

61. Hah N, Danko CG, Core L, Waterfall JJ, Siepel A, Lis JT and Kraus WL: A rapid, extensive, and transient transcriptional response to estrogen signaling in breast cancer cells. Cell 145: 622-634, 2011.

62. Melo CA, Drost J, Wijchers PJ, van de Werken H, de Wit E, Oude Vrielink JA, Elkon R, Melo SA, Léveillé N, Kalluri R, et al: eRNAs are required for p53-dependent enhancer activity and gene transcription. Mol Cell 49: 524-535, 2013.

63. Huarte M and Rinn JL: Large non-coding RNAs: Missing links in cancer? Hum Mol Genet 19R: R152-R161, 2010.

64. Gibb EA, Brown CJ and Lam WL: The functional role of long non-coding RNA in human carcinomas. Mol Cancer 10: 38 , 2011.

65. Tsai MC, Spitale RC and Chang HY: Long intergenic noncoding RNAs: New links in cancer progression. Cancer Res 71: 3-7, 2011.

66. Maruyama R and Suzuki H: Long noncoding RNA involvement in cancer. BMB Rep 45: 604-611, 2012.

67. Spizzo R, Almeida MI, Colombatti A and Calin GA: Long non-coding RNAs and cancer: A new frontier of translational research? Oncogene 31: 4577-4587, 2012.

68. Reference Genome Group of the Gene Ontology Consortium: The Gene Ontology's Reference Genome Project: A unified framework for functional annotation across species. PLoS Comput Biol 5: e1000431, 2009.

69. Mizuma M, Rasheed ZA, Yabuuchi S, Omura N, Campbell NR, de Wilde RF, De Oliveira E, Zhang Q, Puig O, Matsui W, et al: The gamma secretase inhibitor MRK-003 attenuates pancreatic cancer growth in preclinical models. Mol Cancer Ther 11: 1999-2009, 2012.

70. Feng J, Ma T, Ge Z, Lin J, Ding W, Chen H, Zhu W, Zhou S and Tan Y: PKM2 gene regulates the behavior of pancreatic cancer cells via mitogen-activated protein kinase pathways. Mol Med Rep 11: 2111-2117, 2015.

71. Zhang X, Lian Z, Padden C, Gerstein MB, Rozowsky J, Snyder M, Gingeras TR, Kapranov P, Weissman SM and Newburger PE: A myelopoiesis-associated regulatory intergenic noncoding RNA transcript within the human HOXA cluster. Blood 113: 2526-2534, 2009

72. McCarthy DJ and Smyth GK: Testing significance relative to a fold-change threshold is a TREAT. Bioinformatics 25: 765-771, 2009.

73. Su X, Malouf GG, Chen Y, Zhang J, Yao H, Valero V, Weinstein JN, Spano JP, Meric-Bernstam F, Khayat D, et al: Comprehensive analysis of long non-coding RNAs in human breast cancer clinical subtypes. Oncotarget 5: 9864-9876, 2014. 